\title{
How and why do high school teachers use PhET interactive simulations?
}

\author{
Argenta M. Price, ${ }^{1}$ Katherine K. Perkins, ${ }^{1}$ N.G. Holmes, ${ }^{2, *}$ and Carl E. Wieman, ${ }^{2,3}$ \\ ${ }^{I}$ Department of Physics, University of Colorado Boulder, 390 UCB, Boulder, CO 80309 \\ ${ }^{2}$ Department of Physics, Stanford University, 382 Via Pueblo Mall, Stanford, CA 94041 \\ ${ }^{3}$ Graduate School of Education, Stanford University, 382 Via Pueblo Mall, Stanford, CA 94041 \\ *Present address: Laboratory of Atomic and Solid State Physics, Cornell University, 245 East Ave, Ithaca, NY 14853
}

\begin{abstract}
As educational technologies become increasingly important in K-12 physics education, it is important to understand why and how teachers choose to adopt certain technologies. We examined $\sim 2000$ responses from a survey of high school teachers on how they used PhET interactive simulations (mostly in physics) and what value they felt it provided their students. The analysis helps inform what aspects of an educational technology support or hinder its adoption. First, the teachers valued flexibility. They used simulations in multiple ways for a variety of learning goals, primarily: understanding content, science process, and motivation. Second, they often chose implementations in which students control the simulation. Finally, they noted the value of specific affordances: visualization, seeing and controlling what's normally not possible, and manipulation.
\end{abstract}

\section{INTRODUCTION}

Science education innovations, particularly novel technologies, are continually being developed for use in K12 education. There is also a long history of very checkered success with the attempted use of technology in education. An important lesson of this history is that it is not sufficient to only look at the capabilities of an educational technology in evaluating its value and potential impact; one must also look at what features will support its adoption by teachers, and what features determine how it is used by those teachers [1,2]. Looking specifically at simulations and games for teaching science, research has shown they can improve motivation and learning (for reviews, see: [3-5]), but there is little research on why teachers decide to adopt them or how they use them in teaching.

PhET interactive simulations (https://phet.colorado.edu [6]) have been widely adopted, with around 80 million uses in 2017. This wide adoption makes PhET an ideal case study, in which insights from teachers about their use of simulations will help the physics education community understand why and how teachers decide to use a popular technology. This information will also help guide future simulation design. Here we report the results of a survey of almost 2000 high school teachers who use PhET simulations. We focused our analysis around two research questions: "what goals do teachers have when using simulations?" and "how do teachers believe the affordances of the simulations impact their students' learning?"

\section{METHODS}

In 2012-13, PhET conducted an online survey of teachers who use PhET interactive simulations in their teaching [7]. We received responses from 1901 high school teachers in the US, and the open response questions analyzed here had an average of 1361 responses. Respondents mostly used PhET when teaching physics (73\%) and chemistry (48\%). Although this is a large sample, this is a self-selected set of teachers who already used PhET and were motivated to fill out the survey. Therefore, our results cannot provide information about teachers who choose not to use, or do not know about, the simulations. As expected, teachers who responded to the survey like PhET: $86 \%$ said that their teaching is more, or much more, effective for topics where they use PhET.

\section{A. Survey Questions Analyzed}

For this analysis, we focused on two open response questions: "Please explain how PhET impacts your teaching" and "Please explain how PhET impacts your students' learning." We also briefly analyzed responses to two multiple choice questions: "When you use PhET simulations, in what ways do you use them?" and "When you use PhET simulations, what goals are you typically trying to help students achieve?" Responses to the multiple choice questions from high school and college teachers were discussed in more detail in a previous article [7].

\section{B. Coding Rubric for Open Response Questions}

We used a generative coding method to identify emergent themes from the open response questions [8], in which we iteratively identified key themes from a subset of responses, then grouped similar responses into categories and sub-categories. Responses to the two open response questions were found to be similar. Therefore, the two sets 
of responses were combined and coded according to the same scheme. We identified four main categories of responses about teaching and learning impact: Understanding or exposure to content, science process, motivation, and affordances. Individual statements could be coded into multiple categories and sub-categories.

A sample of 200 responses were coded. A second researcher coded a random subset of 50 questions, resulting in category refinement. Interrater agreement on a final coding rubric for each category ranged from $88-98 \%$, and for each sub-category ranged from $78-100 \%$.

\section{RESULTS AND DISCUSSION}

\section{A. Teachers use simulations to accomplish multiple, flexible, learning goals}

Responses to the multiple choice question about teachers' goals when using PhET showed the importance of flexibility. Teachers typically use simulations for multiple goals (an average of 7.6 out of 13). In addition, the top four most cited goals were selected by over half of the teachers: visualize science phenomena or science representations (91\%); develop conceptual understanding (89\%); engage in exploration and discovery, or conduct science inquiry (64\%); and develop enjoyment or interest in science (52\%).

The survey's open response questions about impact on teaching and learning provide additional insight into why and how teachers use simulations. Responses fell into three main categories: "understanding or exposure to content," "science process," and "motivation" (Table I). Showing that they value learning goals beyond content, teachers commented about student experience (science process or motivation categories) nearly as frequently as they mentioned content or understanding $(65.5 \%$ and $68.5 \%$, respectively), and many teachers (42\%) mentioned elements of both understanding and student experience. An interesting question that our data does not answer is whether the teachers who use PhET place more emphasis on student experience than teachers who do not use PhET.

Overall, teacher responses in the "understanding and exposure" category indicate that teachers value simulations as a tool to help students understand relationships, develop conceptual understanding, and more generally expose students to concepts in new ways. Responses in the "understanding" sub-category ranged from general responses like "students learn better," to more nuanced responses about conceptual understanding and understanding relationships. For example, one physics teacher described how simulations allow students to make sense of a mathematical relationship: "it also helps to clear up apparent inconsistencies with Physics problems, like why a negative number shows up when it should be positive (dealing with charges and electric fields). The simulation shows clearly why this happens in relation to distance and magnitude of the charges involved."

Responses that fell into the "exposure to content and concepts" sub-category highlighted the importance of scientific content in the simulations. For example, one teacher described using PhET to expose students to concepts in a more relevant way: "PhET makes concepts such as momentum and potential energy real to them." Some other comments compared simulations to other forms of instruction, such as textbooks or static images, indirectly indicating what teachers perceive as lacking in other educational resources.

Teachers who described goals in the "science process" or "motivation" categories emphasized how using simulations to engage in scientific practices enhances their students' experience. A majority of teachers in the "science process" category described hands on, exploration, or inquiry learning (61\% of science process responders, $35.5 \%$ of all teachers). Many teachers specifically linked hands on exploration to motivation (56\% of motivation responders; $17.5 \%$ of all teachers). For example, "I think they are more engaged because each student controls how the variables

TABLE I: Coded teacher responses to questions about teaching and learning $(\mathrm{N}=200)$

\begin{tabular}{lrr}
\hline \hline Category & $\begin{array}{c}\text { \% of } \\
\text { Teachers }\end{array}$ & $\begin{array}{c}\text { \% of Main } \\
\text { Category } \\
\text { Responses that } \\
\text { Fall in Each } \\
\text { Sub-Category }\end{array}$ \\
\hline Sub-category & $\mathbf{6 8 . 5} \%$ & \\
\hline Exposure/ & $35.5 \%$ & $40.6 \%$ \\
Understanding & $33 \%$ & $37.7 \%$ \\
Understanding & $9 \%$ & $10.3 \%$ \\
Exposure to & $9 \%$ & $10.3 \%$ \\
concepts & $1 \%$ & $1.1 \%$ \\
Learning style & $\mathbf{5 1 . 5 \%}$ & \\
Apply & $35.5 \%$ & $61.2 \%$ \\
Other & $14 \%$ & $24.1 \%$ \\
\hline Science Process & $8.5 \%$ & $14.7 \%$ \\
Hands-on / explore & $\mathbf{3 1 . 5 \%}$ & \\
Manipulate variables & $12.5 \%$ & $30.9 \%$ \\
Experiment & $10.5 \%$ & $25.9 \%$ \\
\hline Motivation & $8 \%$ & $19.8 \%$ \\
Individualize & $6 \%$ & $14.8 \%$ \\
Engagement & $3.5 \%$ & $8.6 \%$ \\
Fun & & \\
Control & & \\
Other & &
\end{tabular}


will be used, creating unique circumstances to interpret." The fact that many teachers connected motivation with the opportunity for inquiry in this way shows that it is beneficial for technologies to not only help students learn explicitly about science practice, but to allow teachers to use engagement in scientific practices for motivational purposes.

A significant number of teachers described specific elements of experimentation, falling into two sub-categories of science process: manipulating variables (14\%), and other elements of conducting scientific experiments, which included predicting and testing or asking scientific questions $(8.5 \%)$. For example, one teacher wrote, "it requires the students to make observations, predictions, and try to match a model to observations which are all great science skill[s]." However, only $8 \%$ of all teachers indicated in the multiple choice question that they typically use PhET for designing experiments. This indicates that the ability to use technology to conduct experiments is a useful and appreciated affordance for some teachers, even if designing experiments is not a concrete goal.

Overall, the open responses affirm that teachers value the flexible design of simulations, using them in many different ways to match their goals and adapt to student differences.

\section{B. Teachers choose implementations in which students control the simulation}

The survey responses also showed that teachers chose to use simulations in ways that allow students to control the simulation. Responding to the multiple choice question about ways teachers use simulations, teachers said they most typically used simulations for in-class activities $(66 \%)$ or labs $(51 \%)$, while only $33 \%$ of teachers said they typically used simulations as demonstrations. In the open response questions, many teachers wrote about hands-on learning $(35 \%)$ or manipulating variables $(14 \%)$, further showing that they are giving students control of the simulation. An example response highlights why teachers use simulations in this way: "It allows me to take an inquiry approach to a topic even though I cannot have the students study the topic in the lab. It is an excellent method for delivering content to hands-on and visual learners."

Teachers also discussed how the interactive nature of the simulations helped students develop understanding. For example, "Especially in subjects where the topic is abstract and students can't see or handle the material, PhET simulations make it easier to understand because they can see and manipulate the interactions." A small but interesting subset of teachers (6\%) also described direct student control or agency, highlighting how student control improves motivation for learning.

\section{Key affordances allow teachers to accomplish their goals}

In deciding whether to use a particular educational technology, teachers will consider what the technology allows them and their students to do: the affordances of the technology. Although no question asked explicitly about affordances, nearly all teachers $(89.5 \%)$ responded to the teaching and learning questions by mentioning one or often more simulation features that they found useful, or actions that the simulation allowed (Fig. 1). Three of the affordance categories mentioned relate directly to elements intentionally built into all PhET simulations: visualizations, the ability to manipulate or interact, and the ability to provide students with individualized experiences [9-11].

Visualizations were the stand-out category of affordance, mentioned by $54 \%$ of teachers, in a variety of contexts. Teachers said that simulations helped students see things or visualize concepts, were good for visual learners, provided better visualizations than static images, and allowed students to see the unseen. A substantial subset (12\%) specifically mentioned visualizing what students would otherwise not be able to see: "PhET allows me to illustrate phenomenon which students could only observe through changes or through the use of a measuring device. The simulations show students exactly what happens as if the students were inside the system themselves." Visuals that are simultaneously engaging, informative, and easy to interpret are appreciated and used in a variety of ways by teachers.

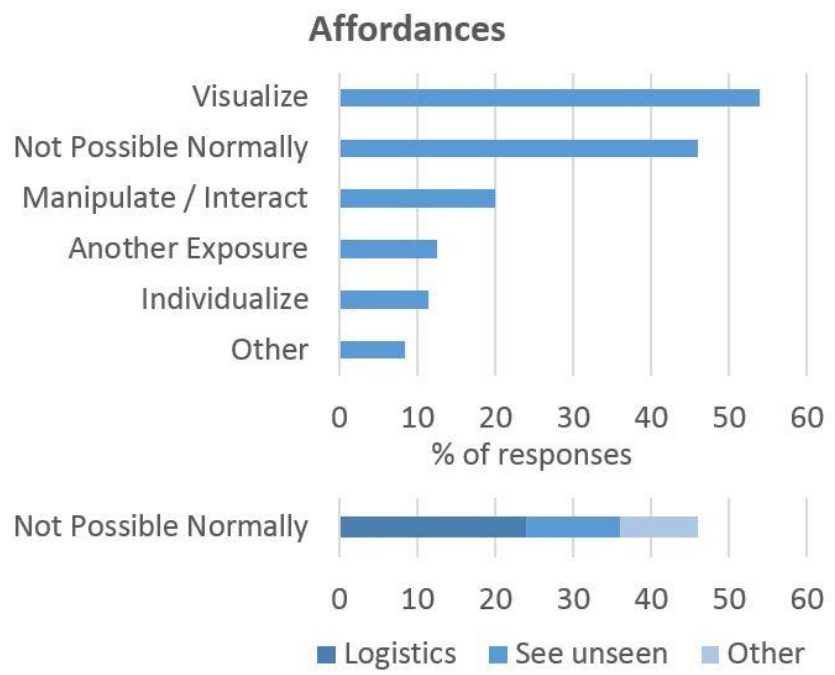

FIG 1. Affordances mentioned in response to teaching and learning questions. The percent of teachers commenting about each affordance, as well as about sub-categories of "not possible normally," is shown. 
Another commonly mentioned affordance was manipulation and interaction (20\% of teachers). Interestingly, many teachers who mentioned manipulation elaborated on how getting immediate feedback was an important aspect of that affordance. For example, one teacher explained that PhET gives "students a hands on example for them to adjust the conditions and immediately see the results." Manipulation with immediate feedback is also an intentional design element of PhET simulations. Combined with implicit scaffolding built into the simulations, this also supports individualized use of the simulations [9]. Some teachers (11.5\%) also commented on using PhET to individualize learning and allow students to control their own learning or pace.

Almost half of teachers $(46 \%)$ described how the simulations added value by allowing activities that are not possible with normal classroom materials. Teachers mentioned overcoming logistical barriers that included ease of use, lack of laboratory equipment, set-up time or activity time, and the cost of materials compared to free simulations. Of teachers who discussed logistical affordances, many specifically mentioned safety; PhET allowed their student to do things like "try it out and experiment without needing special equipment or worrying about dangerous chemicals." Other "not possible normally" affordances were those that allowed teachers to display models and control variables that can't be directly seen or manipulated with real classroom equipment. For example, one teacher described the ability to "perform an experiment under conditions that would otherwise be impossible (no air resistance, friction, etc.)."

The widespread adoption of these simulations is likely due to the overlap between the affordances that teachers appreciate and the features built into their design. Teachers also mentioned some capabilities not available in PhET simulations that they desired, which may be useful for future design. These include the ability to track student participation or outcomes, customizability, and additional guidance either through lesson plans or built into the simulations.

\section{CONCLUSION}

Analysis of this survey showed that teachers appreciated the flexibility of simulations, using them in a variety of ways to accomplish many different goals. In particular, teachers use simulations to help their students develop understanding, engage in scientific processes, and increase motivation. This focus on both the learning of content and the student learning experience should be encouraging to advocates of the Next Generation Science Standards, in which scientific practices are interwoven with content. Possibly even more encouraging is the fact that some teachers explicitly commented about how inquiry, understanding, and motivation were linked.

We were also interested in teachers' thoughts about the affordances of the simulations. They most appreciated visualizations, manipulability, and the ability to do and show things that were otherwise not possible in their classrooms. Our findings provide direction for other educational technology designers by identifying features of PhET simulations that teachers appreciate, and also by noting some capabilities that they might desire in future technologies. The diverse range of implementation methods and goals teachers reported also provides insights into the ways teachers appreciate and leverage this type of technology and highlights the importance of designing technologies that can be used in flexible ways.

\section{ACKNOWLEDGEMENTS}

This work was supported by the National Science Foundation (grant \# 1020362), the William and Flora Hewlett Foundation, and the University of Colorado Boulder.
[1] J. Mueller, E. Wood, T. Willoughby, C. Ross, and J. Specht, Comput. Educ. 51, 1523 (2008).

[2] R. Khatri, C. Henderson, R. Cole, J. E. Froyd, D. Friedrichsen, and C. Stanford, Phys. Rev. Phys. Educ. Res. 12, 10112 (2016).

[3] National Research Council, Learning Science Through Computer Games and Simulations (National Academies Press, Washington, D.C., 2011).

[4] L. K. Smetana and R. L. Bell, Int. J. Sci. Educ. 34, 1337 (2012).

[5] N. Rutten, W. R. van Joolingen, and J. T. van der Veen, Comput. Educ. 58, 136 (2012).

[6] C. E. Wieman, W. K. Adams, and K. K. Perkins, Science 322, 682 (2008).
[7] K. K. Perkins, E. B. Moore, and S. V. Chasteen, in 2014 PERC Proc. (2015), pp. 207-210.

[8] V. Otero and D. Harlowe, in Get. Started PER, edited by C. Henderson and K. Harper (American Association of Physics Teachers, 2009).

[9] W. K. Adams, S. Reid, R. LeMaster, S. McKagan, K. Perkins, M. Dubson, and C. E. Wieman, J. Interact. Learn. Res. 19, 551 (2008).

[10] A. Paul, N. Podolefsky, and K. Perkins, in AIP Conf. Proc. (AIP Publishing, 2013), pp. 302-305.

[11] K. Perkins, N. Podolefsky, K. Lancaster, and E. Moore, in Proc. EdMedia 2012--World Conf. Educ. Media Technol. (AACE, 2012), pp. 436-441. 